\title{
A novel approach using a minimal number of injections during the IVF/ICSI cycle: Luteal half-dose depot GnRH agonist following corifollitropin alfa versus the corifollitropin alfa with a GnRH-antagonist cycle
}

\author{
Bülent Haydardedeoğlu, Esra Bulgan Kılıçdağ \\ Department of Obstetrics and Gynecology, Division of Reproductive Endocrinology and IVF Unit, Başkent University \\ School of Medicine Adana, Turkey
}

\begin{abstract}
Objective: Corifollitropin alfa is a good choice for assisted reproductive technology (ART) cycles because fewer injections are needed than with other agents. In this retrospective cohort, we analyzed luteal injected half-dose depot gonadotropin hormone-releasing hormone (GnRH) agonist cycles in women who received corifollitropin alfa and those who underwent a conventional corifollitropin alfa cycle with a GnRH antagonist.

Material and Methods: In this retrospective cohort, we analyzed luteal injected half-dose depot GnRH agonist cycles in women who received corifollitropin alfa and those who underwent a conventional corifollitropin alfa cycle with a $\mathrm{GnRH}$ antagonist at the Division of Reproductive Endocrinology and IVF Unit, Obstetrics and Gynecology Department, Başkent University School of Medicine, Adana, Turkey, from March 2014 to August 2015. The patient's baseline characteristics were similar between the two groups. Forty-five patients underwent the long protocol, in which a half-dose of depot GnRH agonist was administered on day 21 of the preceding cycle. Forty-nine patients underwent the GnRH-antagonist protocol. Corifollitropin alfa was administered on the menstrual cycle day 3.

Results: The mean ages of the two groups were similar ( $32.77 \pm 5.55$ vs. $34.2 \pm 4.51$ years ["for the long- and antagonist-protocol groups, respectively"]). The total number of retrieved oocytes, the fertilization rate, and the number of transferred embryos were similar between the two groups. The only significant difference between the two protocols was the number of injections during the controlled ovarian stimulation (COH)

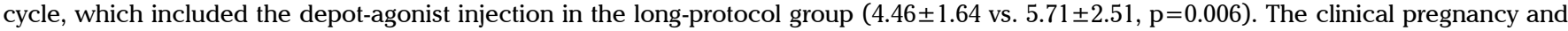
implantation rates were similar in the two protocols (16/45 [35.6\%] vs. 16/49 [32.7\%] for the intention to treat and $32.5 \pm 6.82 \%$ vs. $36.25 \pm 8.58 \%$, respectively).
\end{abstract}

Conclusion: Our results show that ART cycles could be performed with fewer injections using corifollitropin alfa and a half-dose of depot GnRH agonist. (J Turk Ger Gynecol Assoc 2016; 17: 155-8)

Keywords: Corifollitropin alfa, IVF/ICSI outcomes, depot GnRH agonist, GnRH antagonist

Received: 18 March, 2016 Accepted: 27 June, 2016

\section{Introduction}

The clinical excellence of an assisted reproductive technology (ART) program is demonstrated by the live birth of a healthy baby. The many painful injections administered throughout this difficult procedure seem unimportant after a healthy newborn appears. Most women suffering from infertility tolerate this painful time. However, some women drop out of treatment because of the injections (1). Mild ovarian stimulation protocols with clomiphene citrate/letrozole are significant considering that fewer injections are given and that the in vitro fertilization (IVF)/intracytoplasmic sperm injection (ICSI) treatment has a lower cost (2-3). Corifollitropin alfa is a good choice for ART cycles because fewer injections are needed than with other agents. Although the total cost of a corifollitropin alfa cycle is higher than that for the conventional controlled ovarian hyperstimulation $(\mathrm{COH})$ protocol, women tend to select corifollitropin alfa because of the lower number of injections.

Over the last decade, the gonadotropin hormone-releasing hormone $(\mathrm{GnRH})$ antagonist cycle treatment protocol has been favored in ART programs. Although a meta-analysis of cycle outcomes comparing GnRH agonist and antagonist protocols reported similar results, women undergoing the GnRHantagonist program are administered fewer injections and the protocol is easier to perform than agonist protocols (4-5). However, some clinicians continue to prefer the long GnRH agonist cycle. Depot GnRH agonists have been used in ART 
programs before their integration into daily use and have resulted in reasonable outcomes (6-9). Furthermore, the drug industry may force the use of these innovative options, making them more popular. The depot form of recombinant follicle-stimulating hormone (FSH; corifollitropin alfa) is another innovative option that allows for fewer injections during ART cycles.

In the present study, we compared the outcomes of a protocol combining the oldest version of the long protocol, which includes the depot form of GnRH agonist, with corifollitropin alfa to the outcomes of the GnRH-antagonist protocol, which is a rising star of the last decade.

\section{Material and Methods}

In this retrospective cohort, we analyzed luteal injected halfdose depot GnRH agonist cycles in women who received corifollitropin alfa and those who underwent a conventional corifollitropin alfa cycle with a GnRH antagonist at the Division of Reproductive Endocrinology and IVF Unit, Obstetrics and Gynecology Department, Başkent University, Adana, Turkey, from March 2014 to August 2015. This study was approved by the Ethics committee of Başkent University. Ninety-four normal responding women were analyzed in this cohort. Women suspected and/or defined as potential hyper-responders with polycystic ovary syndrome (PCOS) and/or polycystic ovaries (PCO) were excluded and were not administered corifollitropin alfa because of the increased risk of ovarian hyperstimulation syndrome (OHSS).

Forty-five patients underwent the long protocol, in which a halfdose of depot GnRH agonist (1.9 mg leuprolide acetate; Lucrin; Abbott France, Rungis Complexe, France) was administered on day 21 of the preceding cycle. If no cysts $\geq 2 \mathrm{~cm}$ were detectable and estradiol (E2) was $<50 \mathrm{pg} / \mathrm{mL}$, weekly gonadotropin stimulation with $150 \mu \mathrm{g}$ corifollitropin alfa (150 $\mu \mathrm{g}$ Elonva, MSD; Haarlem, The Netherlands) was administered on the menstrual cycle day 3 after ovarian suppression was achieved. The estradiol and follicular monitoring continued until human chorionic gonadotropin (hCG) administration criteria were met and at least three follicles had maximum diameters $>17 \mathrm{~mm}$. Forty-nine patients underwent the GnRH-antagonist protocol. Corifollitropin alfa (Elonva $150 \mu \mathrm{g}$; MSD, The Netherlands) was administered on the menstrual cycle day 3. A GnRH antagonist (Orgalutran, MSD; The Netherlands) was added to this regimen on the last day of weekly gonadotropin administration, which was day 6 of stimulation. The hCG administration was applied with the guidance of ultrasound and estradiol monitoring until at least two or three follicles had maximum diameters $>17 \mathrm{~mm}$. The oocyte retrieval was performed $35-36 \mathrm{~h}$ after the hCG injection performed with a 17-gage needle under sedation. Embryos were transferred on day 3 . All the patients had luteal support with $90 \mathrm{mg}$ daily progesterone administered intravaginally (Crinone $8 \%$ gel, Merck Serono; Darmstadt, Germany) and $0.1 \mathrm{mg}$ / $\mathrm{mL}$ triptorelin on day 3 after embryo transfer. Clinical pregnancy was defined as the presence of at least one gestational sac, with detectable fetal cardiac activity by transvaginal ultrasonography. The data expresses the means \pm SD. The baseline differences between the two groups were analyzed by Student's t test. Pear- son's Chi-square test and Fisher's exact test were used to compare the ratios between groups. A value of $p$ less than 0.05 was considered statistically significant. The data was analyzed using the Statistical Package for the Social Sciences (SPSS) for Windows (version 17.0; SPSS, Inc.; Chicago, IL, USA).

\section{Results}

We performed 94 cycles with corifollitropin alfa in normal responding women during the 17 months of the study. The patients' baseline characteristics were similar between the two groups (Table 1). The mean ages of the two groups were similar $(32.77 \pm 5.55$ vs. $34.2 \pm 4.51$ years ["for the long- and antagonistprotocol groups, respectively"]). Antimüllerian hormone (AMH) levels and mean antral follicle counts (AFC) of one ovary were also similar between the two groups $(2.41 \pm 0.9$ vs. $2.45 \pm 0.45$ $\mathrm{ng} / \mathrm{mL}$ and $5.14 \pm 2.15$ vs. $4.91 \pm 2.41$, respectively) (Table 1 ). Although the mean E2 level on the day of hCG administration tended to be higher in women undergoing the depot-agonist protocol, the difference was not significant (2073.62 \pm 194.18 vs. $1626.5 \pm 188.94 \mathrm{pg} / \mathrm{mL}$ ). The total number of retrieved oocytes, the fertilization rate, and the number of transferred embryos were similar between the two groups (Table 1). The only significant difference between the two protocols was the number of injections during the $\mathrm{COH}$ cycle, which included the depotagonist injection in the long-protocol group $(4.46 \pm 1.64$ vs. $5.71 \pm 2.51, \mathrm{p}=0.006$ ) (Table 1).

The clinical pregnancy and implantation rates were similar in the two protocols (16/45 [35.6\%] vs. 16/49 [32.7\%] for the intention to treat and $32.5 \pm 6.82 \%$ vs. $36.25 \pm 8.58 \%$, respectively) (Table 2). Five and nine cycles were cancelled in the depot-agonist and GnRH-antagonist groups, respectively (Table 2). No moderate or severe ovarian OHSS occurred in either group.

\section{Discussion}

Our results show that IVF/ICSI cycles could be performed with fewer injections using corifollitropin alfa and a half-dose of depot GnRH agonist. The corifollitropin alfa and $\mathrm{GnRH}$-antagonist cycle was introduced so that fewer injections would be needed. Our results show that the half-dose depot $\mathrm{GnRH}$ agonist plus corifollitropin alfa protocol resulted in fewer injections than were required in the GnRH-antagonist program in which corifollitropin alfa was used.

The combination of the depot form of GnRH agonist and corifollitropin alfa is a satisfactory option for patients who plan to drop out of IVF treatment because of the fear of multiple injections. Use of a $\mathrm{COH}$ strategy with fewer injections is associated with $>50 \%$ reduction in dropout rate (1). Although our long protocol with a depot GnRH agonist is not considered to be a mild stimulation, it was superior to mild stimulation, as approximately only four injections were administered, the patients were satisfied, and a greater number of cryopreserved embryos were obtained. Another disadvantage of the protocol is the increased risk for OHSS, which we did not encounter because of our proper selection of normal responding patients.

Depot GnRH agonists have been used since the last decade 
Table 1. Demographic and cycle characteristics of half-dose depot $\mathrm{GnRH}$-agonist and $\mathrm{GnRH}$-antagonist protocols in which corifollitropin alfa was used

\begin{tabular}{|l|c|c|c|}
\hline & $\begin{array}{c}\text { Depot GnRH agonist+ } \\
\text { corifollitropin alfa group (n=45) }\end{array}$ & $\begin{array}{c}\text { GnRH antagonist+ } \\
\text { corifollitropin alfa group (n=49) }\end{array}$ & p \\
\hline Age (years) & $32.77 \pm 5.55$ & $34.2 \pm 4.51$ & 0.17 \\
\hline BMI (kg/m ${ }^{2}$ ) & $24.95 \pm 0.9$ & $25.12 \pm 0.8$ & 0.88 \\
\hline Duration of infertility (years) & $5.23 \pm 3.01$ & $4.72 \pm 3.46$ & 0.45 \\
\hline AMH (m IU/L) & $2.41 \pm 0.9$ & $2.45 \pm 0.45$ & 0.96 \\
\hline Antral follicle count & $5.14 \pm 2.15$ & $4.91 \pm 2.41$ & 0.66 \\
\hline Follicle count $>14$ mm & $11.18 \pm 5.3$ & $10.79 \pm 6.51$ & 0.75 \\
\hline E2 level (pg/mL) on hCG administration day & $2073.62 \pm 194.18$ & $1626.5 \pm 188.94$ & 0.1 \\
\hline Progesterone level (ng/mL) on hCG administration day & $1.07 \pm 0.22$ & $0.88 \pm 0.07$ & 0.42 \\
\hline Endometrial thickness (mm) & $12.57 \pm 1.77$ & $10.92 \pm 1.9$ & 0.33 \\
\hline COH duration & $9 \pm 2.29$ & $8.36 \pm 2.58$ & 0.21 \\
\hline Number of injections in the COH cycle & $4.46 \pm 1.64$ & $5.71 \pm 2.51$ & 0.006 \\
\hline Retrieved oocytes (no.) & $12.22 \pm 7.08$ & $12.95 \pm 7.95$ & 0.64 \\
\hline Metaphase II oocytes (no.) & $9.81 \pm 6.29$ & $10.8 \pm 6.82$ & 0.47 \\
\hline Fertilization rate (\%) & $61.58 \pm 3.14$ & $71.56 \pm 11.96$ & 0.42 \\
\hline Embryo (no.) & $6.65 \pm 4.95$ & $6.29 \pm 3.63$ & 0.7 \\
\hline Transferred embryos (no.) & $1.48 \pm 0.55$ & $1.63 \pm 048$ & 0.22 \\
\hline Grade 1 embryos transferred (no.) & $0.65 \pm 0.69$ & $0.89 \pm 0.68$ & 0.11 \\
\hline Grade 2 embryos transferred (no.) & $0.8 \pm 0.85$ & $0.69 \pm 0.86$ & 0.57 \\
\hline Cryopreserved embryos (no.) & $5.27 \pm 2.37$ & $3.75 \pm 3.06$ & 0.074 \\
\hline $\begin{array}{l}\text { BMI: body mass index; AMH: antimüllerian hormone; COH: controlled ovarian hyperstimulation; E2: estradiol; } \text { hCG: human chorionic gonadotropin; GnRH: gonado- } \\
\text { tropin hormone-releasing hormone }\end{array}$ & & & \\
\hline
\end{tabular}

Table 2. IVF/ICSI outcomes of half-dose depot GnRH-agonist and GnRH-antagonist protocols in which corifollitropin alfa was used

\begin{tabular}{|l|c|c|c|}
\hline & $\begin{array}{c}\text { Depot GnRH agonist+ } \\
\text { corifollitropin alfa group (n=45) }\end{array}$ & $\begin{array}{c}\text { GnRH antagonist+ } \\
\text { corifollitropin alfa group (n=49) }\end{array}$ & \\
\hline Positive $\beta$-hCG & $18(40 \%)$ & $18(36.7 \%)$ & 0.93 \\
\hline CPR & $16(35.6 \%)$ & $16(32.7)$ & 0.95 \\
\hline BPR & $2(4.44 \%)$ & $2(4.08 \%)$ & NS \\
\hline Implantation rate (\%) & $32.5 \pm 6.82$ & $36.25 \pm 8.58$ & NS \\
\hline Singleton pregnancy rate & $13 / 16(81.25)$ & $12 / 16(75 \%)$ & NS \\
\hline Twin pregnancy rate & $3 / 16(18.75 \%)$ & $4 / 16(25 \%)$ & NS \\
\hline OHSS rate & 0 & 0 & 0.46 \\
\hline Cancel rate & $5(11.1 \%)$ & $9(18.4 \%)$ & \\
\hline $\begin{array}{l}\text { CPR: clinical pregnancy rate; BPR: biochemical pregnancy rate; GnRH: gonadotropin hormone-releasing hormone; IVF/CSI: in vitro fertilization/intracytoplasmic } \\
\text { sperm injection; hCG: human chorionic gonadotropin; OHSS: ovarian hyperstimulation syndrome }\end{array}$ &
\end{tabular}

of the $20^{\text {th }}$ century. At that time, the depot agonist was recognized as advantageous because of the attendant pituitary suppression and the patient-friendly requirement of only a single injection. Hesitation to use a depot agonist was related to the concern that it might lead to pituitary oversuppression, which could cause a luteal phase defect because of the absence of pituitary luteinizing hormone $(10,11)$. However, the use of halfdose depot $\mathrm{GnRH}$ for the $\mathrm{COH}$ cycle has resulted in reasonable
IVF outcomes in infertile women (8-9). Therefore, we used half doses of the depot form of GnRH agonist to suppress the ovary. Furthermore, the ultra-long protocol, which includes 3 months of depot GnRH agonist injections to suppress the pituitary and endometriosis, seems to be the best choice in women with endometriosis undergoing IVF/ICSI cycles (12-14). One randomized study that compared depot forms of a GnRH agonist and antagonist reported similar IVF/ICSI outcomes (15). No depot 
GnRH antagonists are marketed in Turkey, but they could be included in another simple protocol with corifollitropin alfa.

The fundamental limitation of this study was the retrospective design. We did not perform a randomized trial because we did not want drug industry support for two reasons. First, our institute must pay all costs, including the costs of the $\mathrm{COH}$ cycles and patient insurance, when a randomized trial is conducted, making it too expensive to design a sufficiently powered randomized study with high patient enrollment without industry support. Moreover, trials supported by a pharmaceutical company would be criticized as being biased in favor of a specific drug.

This is the first study to demonstrate similar IVF/ICSI results from a minimum-injection $\mathrm{COH}$ protocol compared with those from a more conventional method. This minimum-injection protocol is a welcome development that was appreciated by our patients. Our study focused on the long protocol, which most clinicians do not prefer. Additional well-designed randomized trials that compare depot GnRH agonists and antagonists with corifollitropin alfa are expected to demonstrate good IVF/ICSI outcomes.

Ethics Committee Approval: Ethics committee approval was received for this study from the ethics committee of Başent University School of Medicine.

Informed Consent: Written informed consent was obtained from patients who participated in this study.

Peer-review: Externally peer-reviewed.

Author Contributions: Concept - B.H.; Design - B.H.; Supervision - B.H., E.B.K., Resources - B.H.; Materials - B.H.; Data Collection and/or Processing - B.H.; Analysis and/or Interpretation - B.H.; Literature Search - B.H., E.B.K.; Writing Manuscript - B.H.; Critical Review - B.H., E.B.K.; Other - B.H.

Conflict of Interest: No conflict of interest was declared by the authors.

Financial Disclosure: The authors declared that this study has received no financial support.

\section{References}

1. Verberg MF, Eijkemans MJ, Heijnen EM, Broekmans FJ, de Klerk C, Fauser BC, et al. Why do couples drop-out from IVF treatment? A prospective cohort study. Hum Reprod 2008; 23: 2050-5. [Crossref]

2. Verberg MF, Macklon NS, Nargund G, Frydman R, Devroey P, Broekmans FJ, et al. Mild ovarian stimulation for IVF. Hum Reprod Update 2009; 15: 13-29. [Crossref]
3. Mohsen IA, El Din RE. Minimal stimulation protocol using letrozole versus microdose flare up $\mathrm{GnRH}$ agonist protocol in women with poor ovarian response undergoing ICSI. Gynecol Endocrinol 2013; 29: 105-8. [Crossref]

4. Al-Inany HG, Abou-Setta AM, Aboulghar M. Gonadotrophin-releasing hormone antagonists for assisted conception. Cochrane Database Syst Rev 2006; CD001750. [Crossref]

5. Franco JG Jr, Baruffi RL, Mauri AL, Petersen CG, Felipe V, Cornicelli J, et al. GnRH agonist versus GnRH antagonist in poor ovarian responders: a meta-analysis. Reprod Biomed Online 2006; 13: 618-27. [Crossref]

6. Balasch J, Gomez F, Casamitjana R, Carmona F, Rivera F and Vanrell JA. Pituitary-ovarian suppression by the standard and half-doses of D-Trp-6-luteinizing hormone-releasing hormone depot. Hum Reprod 1992; 7: 1230-4.

7. Olivennes F, Righini C, Fanchin R, Torrisi C, Hazout A, Glissant M, et al. A protocol using a low dose of gonadotrophin-releasing hormone agonist might be the best protocol for patients with high follicle-stimulating hormone concentrations on day 3. Hum Reprod 1996; 11: 1169-72. [Crossref]

8. Janssens RM, Lambalk CB, Vermeiden JP, Schats R, Bernards JM, Rekers-Mombarg LT, et al. Dose-finding study of triptorelin acetate for prevention of a premature LH surge in IVF: a prospective, randomized, double-blind, placebo-controlled study. Hum Reprod 2000; 15: 2333-40. [Crossref]

9. Dal Prato L, Borini A, Trevisi MR, Bonu MA, Sereni E, Flamigni C. Effect of reduced dose of triptorelin at the start of ovarian stimulation on the outcome of IVF: a randomized study. Hum Reprod 2001; 16 : 1409-14. [Crossref]

10. Devreker F, Govaerts I, Bertrand E, Van den Bergh M, Gervy C, Englert $\mathrm{Y}$. The long-acting gonadotropin-releasing hormone analogues impaired the implantation rate. Fertil Steril 1996; 65: 122-6. [Crossref]

11. Albuquerque LE, Saconato H, Maciel MC, Baracat EC, Freitas V. Depot versus daily administration of $\mathrm{GnRH}$ agonist protocols for pituitary desensitization in assisted reproduction cycles: a Cochrane Review. Hum Reprod 2003; 18: 2008-17. [Crossref]

12. Barnhart K, Dunsmoor-Su R, Coutifaris C. Effect of endometriosis on in vitro fertilization. Fertil Steril 2002; 77: 1148-55. [Crossref]

13. Surrey ES, Silverberg KM, Surrey MW, Schoolcraft WB. Effect of prolonged gonadotropin-releasing hormone agonist therapy on the outcome of in vitro fertilization-embryo transfer in patients with endometriosis. Fertil Steril 2002; 78: 699-704. [Crossref]

14. Sallam HN, Garcia-Velasco JA, Dias S, Arici A. Long-term pituitary down-regulation before in vitro fertilization (IVF) for women with endometriosis. Cochrane Database Syst Rev 2006; CD004635. [Crossref]

15. Vlaisavljevic V, Reljic M, Lovrec VG, Kovacic B. Comparable effectiveness using flexible single-dose $\mathrm{GnRH}$ antagonist (cetrorelix) and single-dose long GnRH agonist (goserelin) protocol for IVF cycles--a prospective, randomized study. Reprod Biomed Online 2003; 7: 301-8. [Crossref] 